\title{
SOCIAL SUPPORT AND STRESSFUL EVENTS IN TWO DIMENSIONS: LIFE EVENTS AND ILLNESS AS AN EVENT
}

\author{
M. A. R. TIJHUIS, ${ }^{1 *}$ H. D. FLAP, ${ }^{2}$ M. FOETS' and P. P. GROENEWEGEN ${ }^{1,2,3}$ \\ 'NIVEL, Utrecht, The Netherlands, '2Department of Sociology, University of Utrecht, Utrecht, The \\ Netherlands and ${ }^{3}$ Department of Human Geography, University of Utrecht, Utrecht, The Netherlands

\begin{abstract}
Previous research on the buffering effects of social support focused mainly on life events as stressors, and mental illness as outcome. Furthermore, the question as to why support influences illness has not been subjected to theoretical or empirical study much. In this article we develop a hypothesis on the basis of the theory of social capital. We hypothesize that specific types of social resources are more relevant to the consequences of some events than of others. We test this hypothesis in two ways: (1) by taking life events as stressor and occurrence of illness as outcome, and, which is somewhat unusual, (2) by taking illness as stressor and duration and disabilities of illness as the outcome. Analyses of a representative sample of the Dutch population $(N=10,110)$ reveal that receiving specific types of support does not lead to better health or less illness in cases of stress. On the contrary, people who are under stress and receive more support, also appear to report more illness, more disabilities and a longer duration. We suggest that in an open sample like ours, the disease level measured is not severe enough to assess buffer effects of social support.
\end{abstract}

Key words-health, support, life events, illness

\section{INTRODUCTION}

Support is implicated in the aetiology of and recovery from both physical and mental illness [1-7]. Two distinct ideas to explain the relationship between support and health have been put forward. First, the direct effect hypothesis argues that support enhances health and well-being irrespective of level of stress. Secondly, according to the buffering hypothesis, support exerts its effects in the presence of stress, by protecting people from the negative consequences of stress. Direct or buffering processes are established in empirical research when different concepts and types of measurement of social support are used. Direct effects tend to be found when support is measured by the degree to which a person is integrated within a social network, while buffering effects tend to be shown when support is indicated by the availability of resources that help one respond to stressful events [8-11]. In this paper we want to contribute to the study of social support as a buffer of the stress of events.

At present, there is an extensive literature on life events and their effects on mental health, and also some literature on the effects on physical health, although the results with regard to the latter are not straightforward $[12,13]$. The foregoing argument can also be applied to illness itself. Becoming or being ill is also an event that requires adaptation: the length of the illness or the extent of complaints can be mediated by support. The extent to which people succeed in adapting to this type of stress can be learned

\footnotetext{
*Author for correspondence at: RIVM, CCM, HDE, P.O. Box 1,3720 BA Bilthoven. The Netherlands.
}

from the duration of their illness and the degree of disabilities.

The central questions we will try to answer here are:

(1) When we consider stressful life events, does social support buffer their effects on becoming ill?

(2) When we consider illness as stressor, does social support buffer the level of disabilities and duration of that illness?

We expect that, in the case of life events, illness will occur less often when support is provided. In case of illness as the stressor, we expect that the illness will be of shorter duration or will be accompanied by fewer limitations in respect of daily activities when support is provided.

In investigating these hypotheses we take a somewhat different angle than what seems standard in the literature. We argue that buffering effects can only take place when events to be buffered are present. Therefore, we do not analyse the often used interaction of events and support, but instead select respondents who have met specific events. Finding a buffer effect through interaction actually means that people experiencing more events and more support suffer fewer consequences than people experiencing fewer or no events at all or less support or none at all. But we are not interested in the case of fewer or no events for our analyses here, because then there is nothing to buffer. We believe the central issue of the buffer effect is: does support act as a buffer in case of events?

A shortcoming in existing research thus far has been the lack of theoretically developed hypotheses. Why is 
it that support influences illness? Possible answers to this question are sometimes suggested in a rather ad hoc manner $[5,14]$. In this paper we want to make a contribution to the debate on buffering effects by providing some theoretical notions that might explain why some researchers find buffer effects and others do not. These notions are presented in the next section.

\section{A THEORY OF BUFFER EFFECTS}

Social support is seen as a function of personal relations [13]. Different sides to social support like types of social support, experienced or 'objective' support, positively or negatively experienced support are popular topics in the research literature. Today, the idea of social support has been thoroughly examined, but no one version of this concept has been generally accepted. Here, we propose the theory of social capital, which, we believe, makes a contribution to the empirical and theoretical discussion as it has developed.

The theory of social capital assumes that people have access to resources of the people they know [15-17]. These resources are called social or 'second order' resources, meaning that network-members control the social resources ego has access to [18]. In order to achieve certain goals (like health) people can use their personal (e.g. economic, cultural, physical) and their social resources. People with more resources, including social resources, are better able to achieve their goals [19]. People obtain social capital by investing in their social network by way of entering in new relations, or expanding and preserving old relations [16]. The assumption made is that people invest in social relations to guarantee access in the future, or to repay investments made by others in the past. Therefore, social capital is more than a simple count of all people in the network and their personal resources. Social capital is the result of:

(a) the number of people willing to provide support;

(b) the resources that can be mobilized in this indirect manner; and

(c) the extent in which these people are willing or committed to providing support.

From these assumptions it follows that access to social resources does not imply use. The networkmembers who control the resources may already have made great investments in ego in the past: ego does not want to become more indebted [20], or these networkmembers may no longer feel indebted to ego because they see no future repayment from ego [21]. Further, social resources may be goal-specific: "It takes a strong man to carry an invalid" [22]. This may be an explanation for the fact that measures of integration do not, and measures of available resources in times of stress do buffer according to the literature.

In terms of the theory of social capital, the buffer effect concerns those cases in which support is actually mobilized. According to our theory, people may use the social resources they have built up in the past for achieving momentary goals. If their well-being is threatened by stressful events (and we see the occurrence of illness also as a stressor), they can reduce the consequences by resorting to their social resources. When people have more social resources and when they are able to mobilize more of these resources, the consequences of stressful events will be less severe or of shorter duration. This buffer effect will not occur or will do so to a lesser degree if the persons to whose resources one has access to are less socially indebted. Because social resources are often goal-specific it is also possible that the support available is of no use in the specific situation arising. One might suppose that the buffer effect would also be influenced by the availability of professional health care: i.e. when professionals are available, no support from lay network-members is necessary. Since professional providers of support are more or less equally available to all in the Dutch society, we do not imagine that the buffer effect will be influenced to any degree by the presence of professional health care. Studies on the elderly and the chronically ill [22-24], as well as a study on a representative sample of the Dutch [25] give empirical support for this assumption. Moreover, for problems of everyday life there are no standard solutions, which usually are offered by professionals. Social resources are particularly adequate in case of such unpredictable events, in tasks with many contingencies which can not be easily subdivided [22] (p. 10).

Like Litwak [22], Cohen and McKay [26] and Cutrona and Russell [27], who categorized sources and types of social support according to the specific needs of individuals, we assume that specific types of social support are more relevant to the consequences of some events than of others. The characteristics of the specific events and of the types of social support have to match $[5,27]$. A general distinction in types of support can be found in the work of House and Kahn [28] and Schonfeld [29]. The most frequently used categories are emotional support, practical support, informational support and social companionship. We hypothesize that emotional support is more relevant when an event causes anxiety. An event will cause more anxiety if people do not know much about it, if the event does not occur frequently, or if a specific event can not be related directly to a specific cause. There is a need for practical support when the event restricts everyday activities. And information is supposed to benefit people who face events that do require professional help, and when the causes of the events are relatively unknown. Social companionship might influence health or illness directly, but will not be useful in case of buffering the stressors because specific types of support and specific events have to match. We consider social companionship nonspecific, and not meant to exchange any particular kind of support (compare the notion of instrumental 
versus expressive dimensions of social support [30]). Regarding illness as an event, similar hypotheses are proposed, but now with regard to health-related support. We assume that, because events and support have to match, support related to illness is more able to buffer illness as an event than general types of support. Vice versa, general types of support are more able to buffer general types of stress (i.e. other life events than illness) than support related to health.

This theory has much in common with the social support resource theory as developed by Hobfoll [31] and with the theory of optimal matching as developed by Cutrona and Russell [27]. In contrast to these authors [27,31], we focus on 'behavioral social support'. Schwarzer and Leppin [7] label the activation of support, although usually measured by self-reports of receivers, as behavioral support, as it reflects more concrete experience in specific situations. Perceived support, in contrast, reflects general expectations. Schwarzer and Leppin [7] refer to this last kind of support as 'cognitive'.

Perceived support may be most important under normal, everyday circumstances where people can usually cope on their own or have to rely only to a limited degree on others' help. The general sense that one is loved and cared for by others and that these others would help once they are really needed should contribute to psychological and physical well-being. [7] (p. 102)

With the help of the theory of social capital we hypothesized that, for a buffer effect to take place, available resources must be used and match with the need raised by the stressor. Since behavioral support refers to concrete situations, we considered this measurement of support to be optimal to test our hypotheses on buffer effects.

These theoretical notions provide us with a tool to examine the relationships among stressful events, support and illness. The goal-specific nature of social resources, like support, may explain why social support has a buffering effect in some studies and not in others. We hypothesize that, for a buffering effect to take place, the characteristics of specific events and of the mobilized types of social support have to match. To test this hypothesis, we conducted multiple regression analyses on several combinations of types of events and support. The next section gives more details about our data and methods.

\section{DATA AND METHODS}

\section{Data}

Data is gathered as part of the national survey 'Morbidity and Interventions in General Practice' [32] by means of a health interview*. The total sample

*Over 17,000 respondents were selected from the records of 161 general practitioners. Since virtually the entire population of the Netherlands is registered with a general practitioner and since the sample is quite similar to the Dutch population [33], we may consider our sample representative. includes 17,047 respondents, the response rate is $77 \%$. Respondents of all ages are selected, but we have only presented findings for respondents aged 18 and over $(N=10,110)$ here, because this group can be considered to have more freedom in choosing their network-members than younger people. We will first describe the variables used in analyses on life events, and then provide information on details of variables used in the analyses of illness as the stressor. Descriptive statistics of the sample are given in Table 1 .

Life events in our study were measured with the help of two separate lists: life events experienced in the year before the interview [34] and social problems experienced at the moment of the interview [35]. For each list, a sum-score of the number of events or problems was constructed. We decided to use the number of events or problems instead of specific single events on the basis of a literature study by Cohen and Wills [9] in which they conclude that any single event is less likely to be health-threatening. "It is when multiple problems accumulate $[\ldots]$ that the potential for serious disorders occurs" (p. 312). At average, respondents report 1.9 life events and 1.4 social problems (see Table 1). The items on illness in the list of events were not included here, to avoid

Table 1. Descriptive statistics of the sample: percentage of respondents according to gender, age, and to education, prevalence of chronic diseases, minor complaints, psychiatric complaints,and of perceived health status, mean number of social problems, mean number of life events,mean number of days respondents could not carry out their daily routine in the last twomonths (neglecting), mean number of days respondents were confined to bed during the lasttwo weeks (confined to bed), mean number of days respondents have been slowing down inthe last two weeks (quieting) and mean number of disabilities $(N=10,110)$

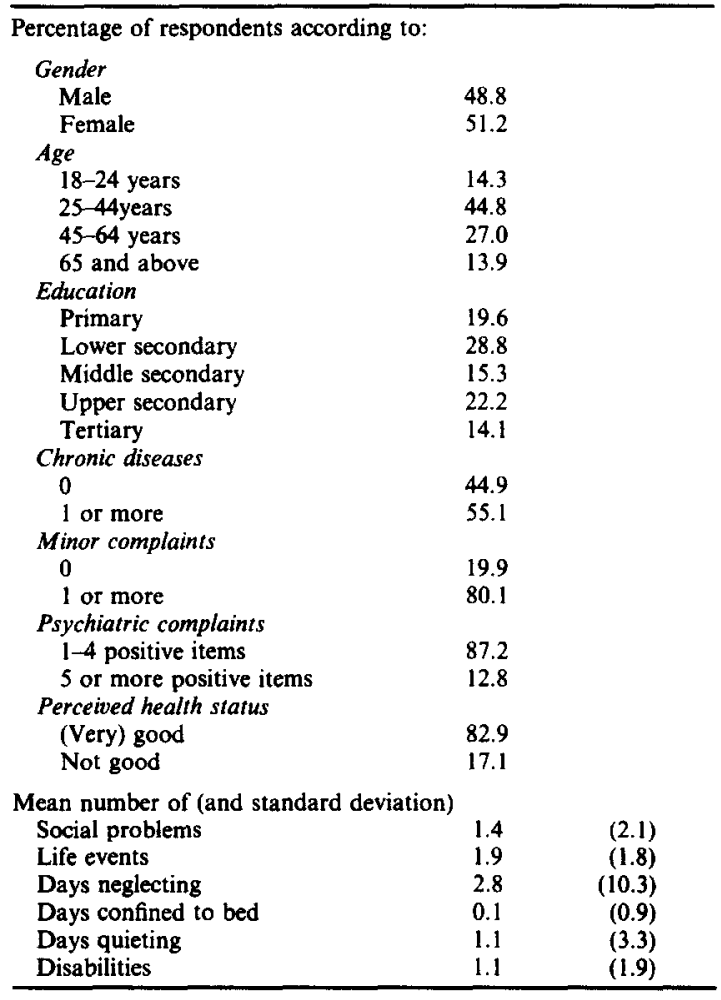


contamination with the measurement of the dependent variable, occurrence of illness. Life events in our list range from death of a spouse to starting a new career. Social problems range from problems in the relation with a partner to problems with housing. To indicate the occurrence of illness we used three indicators: minor complaints, psychiatric complaints and experienced state of health. Minor complaints experienced during the last two weeks prior to the interview were measured by a checklist developed by Foets and Van der Velden [33]. Occurrence of illness is computed by summing all reported complaints and coding this in $0=$ no complaints, $1=1$ or more complaints, per respondent. Nearly $80 \%$ of the respondents report 1

* Of the $\mathbf{4 2}$ complaints in the list, 2 were excluded for this study because they are not direct indicators of (physical or mental) health: problems at work, and family problems. The list contains the following other complaints: fever; general tiredness; general weakness; sweating problems; headache; vertigo/dizziness; throat complaints; ear pain/earache; buzzing; hearing complaints; sneezing/nasal congestion; nose bleed/epistaxis; cough; pressure/tightness attributed to the heart; palpitations/aware of heartbeat; pain attributed to the heart; nausea; vomiting; diarrhoea; heartburn; stomachache or pain; cramps; constipation; teeth/gum complaints; painful urination; incontinence; neck or shoulder complaints; hip complaints; back complaints; arm-, hand-or finger complaints; leg-, thigh, foot- or toe complaints; menstrual pain. These complaints were distinguished in eight groups with the help of the ICPC [36]: general and unspecified complaints; neurological complaints; respiratory and ear complaints; circulatory complaints; digestive complaints; urinary complaints; musculoskeletal complaints and female genital complaints. Prevalence figures range from 1 to $29 \%$.

†Name-generating items were: 'A. Do you talk with people when you have problems with your health? B. When you have a personal problem, do you talk about this with other people? C. Did you receive any help or assistance from people, with regard to a disease in the last few months? D. Did anyone help you with jobs around the house in the last three months? $\mathrm{E}$. When you are away for a longer period of time, do you ask someone to watch the house, water the plants etc.? F. Did you visit anyone last month, or did anyone visit you, or have you been going out with people?' For each item the next question was: 'Can you tell me the names of at maximum three persons?'.

\$These $\mathbf{2 5}$ chronic diseases are (in order of appearance on the check-list): chronic bronchitis/emphysema; asthma; hay fever; hypertension; heart complaints; cardiac failure; haemorrhoids; varices; ulcus cruris; arterio-sclerosis; backache (slipped disc, sciatica); rheumatism/arthritis/ arthrosis; neoplasm/cancer; diseases of the nervous system (Parkinson's disease, multiple sclerosis, epilepsy); migraine/chronic headache; chronic gastro-intestinal disorders; diabetes; gall-bladder and liver diseases; kidney diseases; thyroid gland diseases; prostatism/prostatis; menstruation/menopause complaints; chronic skin diseases/eczema; serious consequences of an accident; hereditary handicaps. Respondents with asthma and chronic bronchitis are included together. Respondents suffering from heart complaints or cardiac failure are also included together, because these diseases belong to the same groups in terms of symptoms. The original list consisted also of an 'other' category. This category was excluded because of suspected minor reliability. or more complaints*. The measure for psychiatric complaints used here is the General Health Questionnaire (GHQ-30, [37]). The GHQ usually is used as a first stage screening instrument of non-psychotic psychiatric illness. Anyone reporting five or more positive items is a possible psychiatric 'case' $[37,38]$. In our study $13 \%$ of all respondents reported five or more positive items. The GHQ must be viewed as measuring present mental health in relation to a 'normal' status. The state of health experienced is measured on a five-point scale $[1=$ very good through $5=$ very bad, recoded to 0 (scores 1 and 2) and 1 (scores 3, 4 and 5)]. 17\% of all respondents experience their current health status as not good.

The central variables of this study are indicators of social support. To assess the amount and kinds of social support we used the exchange method [39]. Six name-generating questions had to be answered, each referring to the provision of a specific type of social support $\dagger$. Respondents were requested to list a maximum of three network-members per question, in reference to people outside the household. Several types of social support can be distinguished: health-related support (see footnote: items $A$ and $C$ ) and support not related to health (items $B, D, E$ and F), and within these categories emotional support (items A or B) and practical support (items $C$ or D and E). Item $F$ is supposed to indicate social companionship, but as mentioned earlier, we have excluded this concept for the present problem at hand. We computed sum-scores for each respondent by counting the number of times the respondent reported receiving a specific type of support. Figures for support-variables can be found in our earlier work [40].

A last indicator of support is the amount of medical information people have access to through networkmembers working (or educated to work) in health care. Nearly half of the respondents had such networkmembers available to them. We acknowledge the fact that the existence of these social relations in the network does not mean that information is received by the respondent. Although we stated in the section on theory that availability of resources does not imply use of them, and that only use of resources might buffer, we can not analyse this to the full extent, because we have no direct data available on receipt of information.

For the analyses on illness as stressor, we measured illness in terms of four indicators of which we already mentioned three (minor- and psychiatric complaints and experienced health status) above. The fourth indicator concerns chronic diseases. The presence of a chronic disease was measured by a checklist developed by Van den Bos [41]. For each of 25 diseases $\ddagger$, the respondent filled in whether he or she suffered from this disease. $55.1 \%$ of all respondents report one or more chronic diseases. This figure is comparable to the results of other studies carried out by the Central Bureau of Statistics in the Netherlands, using the same list of diseases [42]. We did not relate 
life events to the prevalence of chronic diseases, because these diseases generally precede the events and therefore such analyses would be causally incorrect. Several measures were used to indicate the duration of illness. The first is the number of days (in the last two months before the interview) respondents were not able to carry out their daily routine. This variable is labelled 'neglecting'. The second variable is the number of days (in the last two weeks) respondents reported having been 'confined to bed'. The last variable of this kind is the number of days (in the last two weeks before the interview) respondents have been slowing down: 'quieting'. In contrast to the actual duration of an illness these measures can be considered as 'social' duration, or 'social' limitations, because they indicate the consequences illness has for social life. The majority of the respondents (over $80 \%$ ) reported that they did not neglect their daily routine, had been confined to bed or were 'quieting'. An adjusted version of a checklist developed by the OECD*. (OECD-16, [43]) was used to indicate the physical disabilities people meet with. Respondents could report to what extent they were able to perform certain activities themselves. Over $40 \%$ of the respondents experienced one or more disabilities. These may range from not being able to climb the stairs, or not being able to run a $100 \mathrm{~m}$, to not being able to get dressed or cut food. We did not relate minor and psychiatric complaints to the disabilities people experience. These complaints are acute in contrast to the disabilities which may be lifelong. Such analyses would then be causally incorrect. Finally, the support variables employed in the analyses on illness as stressor are the same as the ones we have described above.

\section{Methods}

Like Litwak [22] (and with regard to mental illness: Cohen and McKay [26]) we assume that specific types of social support are more relevant to the consequences of some events than of others. The characteristics of the specific events and of the types of social support have to match. Therefore, we categorized our measures of stress (life events, social problems) according to the supposed buffer effects of the types of support (see Table 2). We categorized these measures of stress ourselves. This may be not the best method. We expect that the life events or social problems in our list require support not related to health. Accordingly, we discuss this categorization below.

We also categorized our measures of illness as event (chronic diseases, minor-, psychiatric complaints and experienced health status) according to the supposed buffer effects of the different types of support. Table 3 shows our expectations regarding the needs for support of people experiencing those illnesses. We expect that these types of illness generally only require

*OECD stands for Organization for Economic Cooperation and Development.
Table 2. Expected need for support per life event or social problem Support. not related to health

practical emotional

\section{Life events:}

You moved, within town

You moved, out of town

You moved out parents house

Your child moved out

Your wife is pregnant, gave birth to a child

Your wife had an abortion or miscarriage*

You stopped working

Other in family stopped working

You started working

Other in family started working

You started school, college, etc.

You quitted school, college, etc.

You got a degree

You/other in family failed to get a degree

Other in family married

Other in family divorced

You/other in family run away

You had a financial success

You had a financial disappointmen

You suffered loss due to theft, fire, violence

Your partner died

Your child died

Your father/mother died

An important other died

You married

You divorced

You/partner had or has an affair

You were promoted

Your pet died

You/other in family was involved in a lawsuit

Social problems:

Financial

Housing

Parents

Education

Work

Getting older

Partner

Children

Important others

Contacts in general

Sexual

Religion

Self-realization

Yourself

Future

Addiction

Loneliness

Changes in society

Neighbourhood

Spending leisure time

Life in general

-For men only.

\begin{tabular}{|c|c|}
\hline+ & 0 \\
\hline+ & + \\
\hline+ & + \\
\hline 0 & + \\
\hline+ & + \\
\hline 0 & + \\
\hline 0 & + \\
\hline 0 & + \\
\hline+ & 0 \\
\hline+ & 0 \\
\hline+ & 0 \\
\hline 0 & + \\
\hline 0 & + \\
\hline 0 & + \\
\hline 0 & + \\
\hline 0 & + \\
\hline+ & + \\
\hline+ & 0 \\
\hline+ & + \\
\hline+ & + \\
\hline+ & + \\
\hline+ & + \\
\hline+ & + \\
\hline 0 & + \\
\hline+ & + \\
\hline+ & + \\
\hline 0 & + \\
\hline 0 & + \\
\hline 0 & + \\
\hline+ & + \\
\hline+ & + \\
\hline+ & + \\
\hline 0 & + \\
\hline+ & + \\
\hline+ & + \\
\hline 0 & + \\
\hline 0 & + \\
\hline 0 & + \\
\hline 0 & + \\
\hline 0 & + \\
\hline 0 & + \\
\hline 0 & + \\
\hline 0 & + \\
\hline 0 & + \\
\hline 0 & + \\
\hline 0 & + \\
\hline 0 & + \\
\hline 0 & + \\
\hline+ & + \\
\hline+ & + \\
\hline 0 & + \\
\hline
\end{tabular}

support that is related to health. We further expect that all chronic diseases require information, because, since these diseases are chronical, professional help might ease the consequences for daily life.

We state clearly that, as we are only considering buffer effects here, and since events or illness are the stressors that are hypothesized to be buffered by social support, we only selected respondents who reported events or illness. We used linear as well as logistic regression analyses. For analyses regarding life events and social problems we are mainly interested in occurrence of illness: does illness not occur when life events or social problems are buffered by social support? Because our data on illness were unable to follow the normal distribution of the 
Table 3. Expected need for support per chronic disease, group of minor complaints, psychiatric complaints, or feeling in bad health

\begin{tabular}{|c|c|c|c|}
\hline & $\begin{array}{c}\text { Health-rela } \\
\text { practical }\end{array}$ & $\begin{array}{l}\text { ted support } \\
\text { emotional }\end{array}$ & information \\
\hline \multicolumn{4}{|l|}{ Chronic diseases: } \\
\hline Arterio-sclerosis & + & + & + \\
\hline Backache (slipped disc, sciatica) & + & + & + \\
\hline Chronic bronchitis/emphysema, or asthma & + & + & + \\
\hline Chronic gastro-intestinal disorders & + & + & + \\
\hline Chronic skin diseases/eczema & 0 & + & + \\
\hline Diabetes & 0 & + & + \\
\hline \multicolumn{4}{|l|}{ Diseases of the nervous system } \\
\hline (Parkinson disease, multiple sclerosis, epilepsy) & + & + & + \\
\hline Gall-bladder and liver diseases (incl. bilestones) & + & + & \\
\hline Haemorrhoids & 0 & 0 & + \\
\hline Hay fever & 0 & 0 & + \\
\hline Heart complaints, or cardiac failure & + & + & + \\
\hline Hereditary handicaps & + & + & + \\
\hline Hypertension & 0 & + & + \\
\hline Kidney diseases (incl. kidney stones) & + & + & + \\
\hline Menstruation/menopause complaints" & + & + & + \\
\hline Migraine/chronic headache & + & + & + \\
\hline Neoplasm/cancer (incl. leukaemia) & + & + & + \\
\hline Prostatism/prostatitis ${ }^{b}$ & + & + & + \\
\hline Rheumatism/arthritis/arthrosis & + & + & + \\
\hline Serious consequences of accident & + & + & + \\
\hline Thyroid gland diseases & + & + & + \\
\hline Ulcus cruris & + & + & + \\
\hline Varices & + & + & + \\
\hline \multicolumn{4}{|l|}{ Minor complaints: } \\
\hline General and unspecified & + & + & + \\
\hline Neurological & + & + & + \\
\hline Respiratory & 0 & 0 & 0 \\
\hline Digestive & + & + & 0 \\
\hline Circulatory & + & + & + \\
\hline Musculoskeletal & + & 0 & + \\
\hline Urinary & 0 & 0 & + \\
\hline Female genital & + & + & + \\
\hline Psychiatric complaints & + & + & + \\
\hline Feeling in bad health & + & + & + \\
\hline
\end{tabular}

'For women only.

'For men only.

errors as assumed for linear regression and because we are interested in occurrence (and not number) of complaints, we conducted logistic regression analyses [44]. For the analyses on illness as event we are interested in buffer effects of support on level of disabilities and 'social' duration. Since the dependent variable for this type of analysis is continuous (the number of disabilities, or the number of days respondents neglected daily routine, or have been confined to bed, or have been quieting)*, we performed linear regression analyses. Because a majority of the respondents did not report disabilities or neglecting their daily tasks etc., these dependent variables had to be transformed to be able to apply linear regression analyses. Best fitting results with

"Another option for dealing with this problem is to recode the dependent variable in a dichotomous way. Then the question is not whether social support infiuences the number of disabilities, days neglecting routine etc., but whether social support influences the occurrence of disabilities or neglecting routine etc. Neglecting routine, being confined to bed and 'quieting' must then also be considered as a kind of disability. Such a dichotomized dependent variable demands for logistic regression analyses. Anyway, whether we performed linear or logistic regression analyses, results were always quite the same. regard to residuals and outliers [45] were obtained by transforming the dependent variable with a square root: $\sqrt{ } y+\sqrt{ }(y+1)$, where $y=$ dependent variable. These data were now more able to follow the normal distribution of the errors. All coefficients are tested for significance at a one-tail $P<0.05$ level.

Because types of support seem to overlap, we admitted only one type of support in each equation. When practical support is provided, for instance, people most often also experience emotional support. In order to distinguish these different types of support, we elicited them separately and also employed them in separate analyses.

In an attempt to take possible confounders into account, age, gender, education and the number of events or complaints were included in the analyses as control-variables. The number of events or complaints was included to indicate severity. We included the number of events or complaints only for the same category of events or complaints. All variables in regression analyses were used as continuous variables, except gender. Gender is a dummy-variable: $1=$ male. Education is coded as $1=$ low, $5=$ high.

Of course, we also conducted bi-variate analyses. To be able to determine whether events do relate to illness 
in general, and whether support relates to illness in general, we computed product moment correlations for our total sample. These are shown in Appendices $A$ and $B$, and will be discussed in the next sections when appropriate.

\section{RESULTS}

First, we describe results for our categorization of stress-measures according to the supposed buffer effects of the types of support. Correlations (Pearson product-moment, [46]) between events requiring specific kinds of support (not related to health) and perceiving this kind of support are given in Appendix C. Although the statistical significance of low correlations might be due to the large sample size, these correlations nevertheless indicate that our categorization could be useful. These correlations are calculated for each number of events or problems in combination with the receipt of one particular type of support. All correlations indicate that the experience of more life events or social problems is related to the experience of more support. Relationships of life events and social problems requiring emotional support with receiving emotional support are statistically significant. The relationships of life events or social problems requiring practical support and receiving practical support are not statistically significant. Because the lists of events or problems requiring emotional or practical support partially overlap, the finding that correlations with the receipt of both types of support are statistically significant does not surprise us, although we would have expected stronger correlations with the matching type of support. Further, we see that these stressors are also related to the receipt of health-related types of support. We assume that, although the list of events and problems did not incorparate items on health problems, these correlations are due to the fact that people very often also experience health problems.

Correlations between types of illness and all types of health-related support are also given in Appendix C. Experiencing more chronic diseases, more minor complaints, psychiatric complaints and feeling in bad health is generally related to receiving health-related emotional and practical support. For the availability of sources of information, the correlations with measurements of illness as stressor are mostly negative. Experiencing chronic diseases is generally related to perceiving less sources of information. Experiencing minor and psychiatric complaints, or feeling in bad health is not significantly related to receiving sources of information.

*To take the possible confounding effect of severity into account, we also conducted analyses for people with and without chronic comorbidity (not shown here). We found no important differences between these analyses.
Correlations between one type of support and categories of, for instance, chronic diseases are always quite the same. This is due, of course, to the fact that the chronic diseases in each category overlap: one chronic disease often requires several kinds of support. The same is true for the categories of minor complaints.

Half of the correlations between types of support not related to health (emotional support in particular) and types of illness as stressor are also statistically significant. Suffering from a particular illness, of course, does not mean that only health-related matters are experienced. People who suffer from illness, probably also experience certain other life events or social problems. In further analyses, buffer effects of all kinds of support are estimated with regard to all kinds of stressors.

The next paragraphs in this results section concern the hypothesized buffer effects.

\subsection{Social support in relation to life events}

That events coincide with more health complaints can be concluded from Appendix A: the number of events or problems and the number of specific complaints are all positively related. The results of testing the hypothesis that support buffers the effects of events or problems on reported complaints are shown in Table 4. The main conclusion to be drawn is that there is just one statistically significant (negative) coefficient in accord with our hypothesis: people who reported social problems requiring emotional support (all problems in our list) and who also have resources available who might give them health-related information, appear to report feeling in bad health less often (coefficient $=-0.38$ ). What appears more clearly is that people experiencing complaints also receive more support, specifically health-related emotional and practical support.

\subsection{Social support in relation to illness as stressor}

All types of self-reported illness are positively and statistically significant related to the 'social' duration of illness and disabilities (Appendix B). Findings on the hypothesis about buffer effects of social support on the 'social' duration and disabilities of chronic diseases are in line with the conclusions above (see Table 5)*.

Health-related support has no buffer effects: people who report a longer duration and more disabilities, receive more health-related support than people who report a shorter duration or fewer disabilities. An exception here is information: people with chronic diseases report fewer disabilities in combination with the availability of sources of information (coefficients are: for chronic diseases requiring emotional support -0.15 , for chronic diseases requiring practical support -0.17 , for chronic diseases requiring information -0.15 , all are statistically significant at a level of $P<0.001$ ).

In all regression equations regarding people with minor complaints, the signs of support-variables are 
Table 4. Non-standardized logistic regression coefficients for each type of support per dependent variable, for people with social problems or life events requiring emotional or practical support, analyses are controlled for gender $(0=$ female, $1=$ male), age (continuous), education $(1=l o w$, through $5=$ high), and number of problems or events in each group of problems of events

\begin{tabular}{|c|c|c|c|}
\hline & $\begin{array}{c}\text { Occurrence of } \\
\text { minor } \\
\text { complaints }\end{array}$ & $\begin{array}{l}\text { Psychiatric } \\
\text { complaints }\end{array}$ & $\begin{array}{l}\text { Feeling in } \\
\text { bad health }\end{array}$ \\
\hline \multicolumn{4}{|c|}{ (1) For people experiencing social problems requiring emotional support $(N=3226)$} \\
\hline Emotional support, not related to health & 0.21 & 0.16 & -0.17 \\
\hline Practical support, not related to health & 0.15 & 0.02 & -0.01 \\
\hline Emotional support, related to health & $0.63^{* * *}$ & $0.32^{* * *}$ & $0.50^{* * *}$ \\
\hline Practical support, related to health & 0.55 & $0.68 * * *$ & $0.92^{* * *}$ \\
\hline Information, related to health & 0.01 & -0.09 & $-0.38 * * *$ \\
\hline \multicolumn{4}{|c|}{ (2) For people experiencing social problems requiring practical support $(N=651)$} \\
\hline Emotional support, not related to health & 0.20 & 0.28 & 0.03 \\
\hline Practical support, not related to health & 0.15 & 0.08 & 0.15 \\
\hline Emotional support, related to health & $0.93^{* *}$ & 0.32 & 0.36 \\
\hline Practical support, related to health & 0.39 & 0.36 & $1.42^{* * *}$ \\
\hline Information, related to health & -0.04 & -0.09 & -0.28 \\
\hline \multicolumn{4}{|c|}{ (3) For people experiencing life events requiring emotional support $(N=2259)$} \\
\hline Emotional support, not related to health & $0.23^{*}$ & $0.57^{* * *}$ & 0.07 \\
\hline practical support, not related to health & $0.32 * * *$ & 0.06 & 0.07 \\
\hline emotional support, related to health & $0.93^{* * *}$ & $0.65^{* * *}$ & $0.57 * * *$ \\
\hline practical support, related to health & $1.32 * * *$ & $1.01 * * *$ & $1.47^{* * *}$ \\
\hline information, related to health & -0.07 & -0.03 & -0.12 \\
\hline \multicolumn{4}{|c|}{ (4) For people experiencing life events requiring practical support $(N=1733)$} \\
\hline Emotional support, not related to health & $0.40^{* *}$ & $0.58 * * *$ & -0.03 \\
\hline Practical support, not related to health & $0.23^{*}$ & -0.01 & 0.04 \\
\hline Emotional support, related to health & $1.08 * * *$ & $0.83^{* * *}$ & $0.59 * * *$ \\
\hline Practical support, related to health & $1.45^{* * *}$ & $0.91 * * *$ & $1.44^{* * *}$ \\
\hline Information, related to health & 0.09 & -0.16 & -0.08 \\
\hline
\end{tabular}

Statistical significance: ${ }^{*} P<0.05 ;{ }^{* *} P<0.01 ; * * P<0.001, t$-test.

positive, indicating that respondents reporting more days neglecting the routine, being confined to bed and quieting experience more support, health-related* or not. Results for people with psychiatric complaints are that health-related support has no buffer effect, and that the possible buffer effects of emotional support not related to health are not statistically significant (coefficients are: for number of days neglecting daily tasks -0.27 , for number of days being confined to bed -0.09 , for number of days quieting -0.29 ). That emotional support not related to health might buffer the effects of psychiatric complaints (vs the non-buffering effects of emotional support related to health) may not be strange since our measures of support clearly distinguish between health problems and personal problems. Respondents may view psychiatric complaints as personal problems and not as health problems. Results for people feeling in bad health are all in line with the results for people

*We also carried out separate regression analyses for respondents experiencing minor complaints divided in those with and without paid employment. Perhaps people misinterpreted the question about neglecting their daily routine as only referring to work. There are no important differences in signs and statistical significance of coefficients for support variables between employed and unemployed people. Another possible reason why we did not find any buffer effects could be that the support measures only refer to people outside of the household. For this reason we performed all regression analyses both for people living alone and for those not living alone. Again, no differences were found with regard to buffering minor complaints. experiencing minor complaints: people experiencing longer duration perceive more support.

Because most of our respondents report no days of neglecting daily tasks, being confined to bed or quieting at all, and nearly $60 \%$ reports having no disabilities, we decided to perform the analyses shown in Table 5 for respondents reporting at least one day of being constrained through illness or at least one disability. This may be also another way of controlling for severity of illness to a certain extent. People who have suffered at least some consequences of their illness, as indicated by the report of a disability or a day of quieting etc., may be all more severely ill than people who have not suffered these consequences recently. In Appendix D we show the results of these analyses. They indicate that, to some extent, buffer effects might exist for this group of respondents. More coefficients of support variables show the expected buffer effect, namely 13 as compared to 3 in Table 5. Nearly half of all coefficients in Appendix D appear to have a negative sign (the 'sign' of buffering), whereas in Table 5 only 11 out of all 135 coefficients do. More in detail, the availability of sources of information appears to be related negatively to the number of days being confined to bed and the number of disabilities. Coefficients of emotional support not related to health reach statistical significance in the number of days quieting in the case of people experiencing chronic diseases requiring emotional support $(-0.25)$, and requiring information $(-0.30)$, and also in the case of people experiencing minor complaints requiring information $(-0.22)$. We will discuss these results in the next section. 
Table 5. Non-standardized linear regression coefficients for each type of support per dependent variable for people with illness as stressor, analyses are controlled for gender $(0=$ female, $1=$ male), age (continuous), education ( $1=$ low, through $5=$ high), and number of diseases or complaints in each group of diseases or complaints

\begin{tabular}{|c|c|c|c|c|}
\hline & \multicolumn{3}{|c|}{ Number of days } & \multirow[b]{2}{*}{$\begin{array}{l}\text { Number of } \\
\text { disabilities }\end{array}$} \\
\hline & Neglecting & $\begin{array}{l}\text { Confined } \\
\text { to bed }\end{array}$ & Quieting & \\
\hline \multicolumn{5}{|c|}{ (I) For people experiencing chronic diseases requiring emotional support $(N=5042)$} \\
\hline Emotional support, not related to health & $0.22^{*}$ & 0.01 & 0.08 & 0.01 \\
\hline Practical support, not related to health & $0.37^{* * *}$ & $0.05^{* * *}$ & $0.20^{* * *}$ & -0.03 \\
\hline Emotional support, related to health & $0.60^{* * *}$ & $0.06^{* *}$ & $0.41^{* * *}$ & $0.11^{* *}$ \\
\hline Practical support, related to health & $2.83^{* * *}$ & $0.41^{* * * *}$ & $1.50^{* * *}$ & $0.83^{* * * *}$ \\
\hline Information, related to health & 0.11 & 0.02 & 0.09 & $-0.15^{* * *}$ \\
\hline \multicolumn{5}{|c|}{ (2) For people experiencing chronic diseases requiring practical support $(N=4362)$} \\
\hline Emotional support, not related to health & 0.21 & 0.01 & 0.10 & -0.01 \\
\hline Practical support, not related to health & $0.36 * * *$ & $0.06 * *$ & $0.22^{* * *}$ & -0.03 \\
\hline Emotional support, related to health & $0.62 * * *$ & $0.06^{*}$ & $0.41^{* * *}$ & $0.13^{* *}$ \\
\hline Practical support, related to health & $2.81^{* * *}$ & $0.44^{* * *}$ & $1.50^{* * *}$ & $0.86^{* * *}$ \\
\hline Information, related to health & 0.09 & 0.02 & 0.07 & $-0.17^{* * *}$ \\
\hline \multicolumn{5}{|c|}{ (3) For people experiencing chronic diseases requiring information $(N=5509)$} \\
\hline Emotional support, not related to health & 0.17 & 0.01 & 0.08 & -0.01 \\
\hline Practical support, not related to health & $0.37^{* * *}$ & $0.05^{* * *}$ & $0.18^{* * *}$ & -0.04 \\
\hline Emotional support, related to health & $0.61^{* * *}$ & $0.06^{* *}$ & $0.42^{* * *}$ & $0.11^{* *}$ \\
\hline Practical support, related to health & $2.81^{* * *}$ & $0.39^{* * *}$ & $1.43^{* * *}$ & $0.81^{* * *}$ \\
\hline Information, related to health & 0.07 & 0.02 & 0.06 & $-0.15^{* * *}$ \\
\hline \multicolumn{5}{|c|}{ (4) For people experiencing minor complaints requiring emotional support ( $N=6264)$} \\
\hline Emotional support, not related to health & 0.07 & 0.01 & 0.05 & - \\
\hline Practical support, not related to health & $0.32^{* * *}$ & $0.05^{* * *}$ & $0.18^{* * *}$ & - \\
\hline Emotional support, related to health & $0.48^{* * *}$ & 0.03 & $0.36^{* * *}$ & - \\
\hline Practical support, related to health & $2.63^{* * *}$ & $0.41^{* * *}$ & $1.29^{* * *}$ & - \\
\hline Information, related to health & 0.08 & 0.02 & $0.10^{*}$ & - \\
\hline \multicolumn{5}{|c|}{ (5) For people experiencing minor complaints requiring practical support $(N=7142)$} \\
\hline Emotional support, not related to health & 0.04 & 0.01 & 0.01 & - \\
\hline Practical support, not related to health & $0.31^{* * *}$ & $0.04^{* * *}$ & $0.17^{* * *}$ & - \\
\hline Emotional support, related to health & $0.44^{* * *}$ & 0.03 & $0.33^{* * *}$ & - \\
\hline Practical support, related to health & $2.69^{* * *}$ & $0.40^{* * *}$ & $1.31^{* * *}$ & - \\
\hline Information, related to health & 0.05 & 0.02 & 0.07 & - \\
\hline \multicolumn{5}{|c|}{ (6) For people experiencing minor complaints requiring information $(N=6874)$} \\
\hline Emotional support, not related to health & 0.06 & 0.01 & 0.02 & - \\
\hline Practical support, not related to health & $0.30^{* * *}$ & $0.04^{* * *}$ & $0.17^{* * *}$ & - \\
\hline Emotional support, related to health & $0.44^{* * *}$ & $0.03^{*}$ & $0.33^{* * *}$ & - \\
\hline Practical support, related to health & $2.68^{* * * *}$ & $0.41^{* * *}$ & $1.32^{* * *}$ & - \\
\hline Information, related to health & 0.05 & 0.01 & 0.06 & - \\
\hline \multicolumn{5}{|c|}{ (7) For people experiencing psychiatric complaints $(N=1221)$} \\
\hline Emotional support, not related to health & -0.27 & -0.09 & -0.29 & - \\
\hline Practical support, not related to health & $0.59 * *$ & $0.11^{*}$ & $0.38^{* * *}$ & - \\
\hline Emotional support, related to health & $0.66^{*}$ & 0.10 & $0.52^{* * *}$ & - \\
\hline Practical support, related to health & $3.52^{* * *}$ & $0.65^{* * *}$ & $1.68^{* * *}$ & - \\
\hline Information, related to health & 0.52 & 0.01 & 0.28 & - \\
\hline \multicolumn{5}{|l|}{ (8) For people feeling in bad health $(N=1693)$} \\
\hline Emotional support, not related to health & 0.41 & 0.07 & 0.25 & - \\
\hline Practical support, not related to health & $0.61^{* * *}$ & $0.12^{*}$ & $0.39^{* * *}$ & - \\
\hline Emotional support, related to health & $0.64^{* *}$ & 0.06 & $0.41^{* *}$ & - \\
\hline Practical support, related to health & $2.65^{* * *}$ & $0.47^{* * *}$ & $1.42^{* * *}$ & $\ldots$ \\
\hline Information, related to health & 0.36 & 0.03 & $0.41^{* *}$ & - \\
\hline
\end{tabular}

Statistical significance: ${ }^{*} P<0.05 ;{ }^{* *} P<0.01:{ }^{* * *} P<0.001, t$-test.

Regression analyses for people experiencing minor-, psychiatric complaints and feeling in bad health with number of disabilities are not included: these complaints are acute while disabilities may have been present for a longer period of time. Such analyses then, would be causally incorrect.

\section{CONCLUSION AND DISCUSSION}

The main result of this study is that receiving support does not coincide with better health or less illness in cases of stress. On the contrary, especially perceiving practical support related to health is associated with occurrence of illness, a greater number of disabilities and a longer duration. An explanation for these results has been hinted at earlier by DunkelSchetter and Wortman [47], Avis et al. [48] and Schwarzer and Leppin [7]. With cancer as the stressful event and symptoms and physical functioning as dependent variables, Dunkel-Schetter and Wortman [47] conclude that stress can bring about increased support that could mistakenly be viewed as a negative buffering effect even in longitudinal studies. Schwarzer and Leppin [7] call this phenomenon a 'mobilization' effect. In our case this probably means that we did not take the severity of the complaints sufficiently into account, because 'mobilization' could be caused by the fact that people who are more severely ill also need more support than those less severely ill. Studies by 
Ros [49] and Glass and Maddox [50] show that buffereffects are found for severely ill people. Schonfeld [29] argues that when severely threatening life events are rare in a sample, a study does not provide an optimum context for examining stress buffering effects. In this study we have tried to take the severity of complaints into account by controlling for the number of events or complaints. We also conducted separate analyses for people who can be considered more severely ill on grounds of other measurements and those who probably are less severely ill. Finally, for illness as stressor, we also performed analyses for people who reported at least one day of being constrained because of their illness or at least one disability, assuming that these people would be more severly ill than people who did not report these consequences. Although we found an increased number of indications of buffer effects for this group, this number was still not very convincing. However, to examine the effect of severity into more depth, one needs a case-control study in which more specific data on physical and mental condition are available.

Systematic buffer effects are not found in our analyses. Buffer effects are found sometimes in the case of information available through persons working in health care: more health-related information available relates to fewer complaints, shorter duration and fewer disabilities for people suffering from chronic diseases. Nevertheless, the number of relationships indicating buffer effects is too small to be conclusive. Support not related to health does not show buffer effects systematically and this type of support does not often show statistically significant relationships at all.

Methodological objections could be made. For instance, we employ cross-sectional data to test hypotheses on a longitudinal process. Still, we hardly ever find buffer effects for support not related to health, while other researchers in this area, also using cross-sectional data, did find buffer effects, for physical illness too. One reason may be for minor complaints, that they usually are present for such a short period that support simply does not get a chance to buffer its course. One could also criticise our measurement of the length of illness behaviour. This length was limited to two months or two weeks before the interview, but this period may have continued after the interview or may have started before the two month or two weeks period. We do not have a remedy for this problem. Further, all measurements were reported by the respondents themselves. For the support measure for instance this means that only people who experienced the receipt of support report this, for people who did not experience support we have no data on support available. Then, there is the problem of matching types of events and support. We categorized events in a rather ad hoc manner. Future studies have to test this categorization. A final remark involves the time-frames of all variables used. Imposing a causal order on the measures used is not that easy, even more so since the support-variables each refer to different time-frames.

But, notwithstanding these remarks, the design of our study has some clear advantages over those of others. For instance, we studied life events as well as illness as stressor. Furthermore, the buffer effects of social support on the occurrence of physical illness have not been studied very often (we can only recall one earlier study: [51]). Even more advanced in this field is our investigation into the duration and accompanying disabilities of the illness with regard to illness as a stressor. This clearly fills a gap in the research literature on buffer effects. Not only is physical illness rarely studied, if it is, researchers only examine utilization of health services or recovery [2]. There are still other methodological advantages in our study worth recalling. The data are gathered for a representative sample. And most important, the idea of necessity of a match between types of support and illness for the occurrence of buffer effects, has been empirically tested in this study. As, in contradistinction to most earlier studies, we have data at our disposal on several types of illness and support, we were able to combine types of support and types of events in our analyses. Although other authors also report on matching events and support [48-49,52-56], this line of research is rare in the international literature. Unfortunately, we have very few results worth mentioning on the validity of matching types of support and illness.

In considering the properties of our investigations here, we think that the lack of empirical results confirming the buffer effect can not be completely attributed to faults in design and measurement. The only measure of support that shows buffer effects sometimes is 'available information'. These results are open to several possible interpretations. For one, it may be that social support does not buffer the duration or disabilities of illness in an open population. The events or diseases studied might also be not severe enough for the buffer effect to function. The suggestion for future research to be concluded from this is that social support should be asked for more specifically, in relation to specific events, and that also the measure of illness, or duration and disabilities must be much more specific, and of course, longitudinal.

Another option is to withdraw the mechanism of buffer effects as we described it in terms of actual use of resources. Since health-related information is measured indirectly, as access to health professionals, we probably have measured some kind of integration instead of the receipt of support. The mechanism proposed alternatively is of a more psychological nature. This other possible path consists of direct psycho-physiological changes (like elevated blood pressure) instigated by members of the social network, that influence disease susceptibility. Less exposure to social contacts then, is expected to produce a worse physiological or psychological status that could produce occurrence of health complaints [14]. This 
possible mechanism is expected to work irrespective of stress level. Previous analyses [57] indicated that other measures of integration, especially household composition, are positively related to health. Some first provisional analyses on a selection of people experiencing chronic diseases (not shown) indicate that not living alone, being member of a church, being member of a voluntary organization, reporting more friends and a higher number of support-givers overall, is related to reporting less disabilities. The causal direction of these results has to be determined by longitudinal analyses, because it is possible that these measures of integration protect health, but it is also possible that it is health status that determines the degree of social integration.

Acknowledgement-The work reported here is supported by a grant (NWO, Grant Number $500-279-202$ ) as part of a larger study on social networks and health.

\section{REFERENCES}

1. Leavy R. L. Social support and psychological disorder: a review. J. Commun. Psychol. 11, 3, 1983.

2. Wallston B. S., Alagna S. W., DeVellis B. M. and DeVellis R. F. Reviews. Social support and physical health. Hlth Psychol. 2, 367, 1983.

3. Wortman C. B. and Conway T. L. The role of social support in adaptation and recovery from physical illness. In Social Support and Health (Edited by Cohen S. and Syme S.L.), p. 281. Academic Press, New York, 1985 .

4. Ganster D. C. and Victor B. The impact of social support on mental and physical health. Br.J. Med. Psychol. 61, $17,1988$.

5. Cohen S. Psychosocial models of the role of social support in the etiology of physical disease. Hlth Psychol. 7, 269, 1988.

6. Cohen, S. Social supports and physical health: symptoms, health behaviours, and infectious disease. In Life-span Developmental Psychology: Perspective on Stress and Coping (Edited by Cummings M., Greene A. L. and Karraker K. H.), p. 213. Lawrence Erlbaum, Hillsdale/New York, 1989.

7. Schwarzer R. and Leppin A. Social support and health: a theoretical and empirical overview. J. Soc. Personal Relationships 8, 99, 1991.

8. Cohen S. and Syme S. L. Issues in the study and application of social support. In Social Support and Health (Edited by Cohen S. and Syme S. L.), p. 3. Academic Press, New York, 1985.

9. Cohen S. and Wills T. A. Stress, social support and the buffering hypothesis. Psychol. Bull. 98, 310, 1985.

10. Israel B. A. and Rounds K. A. Social networks and social support: a synthesis for health educators. Adv. Hith Educ. Promotion 2, 311, 1987.

11. Van Sonderen F. L. P. Het meten van sociale steun (Measuring social support). Universiteitsdrukkerij, Groningen, 1991.

12. Tausig M. Measuring life events. In Social Support, Life Events, and Depression (Edited by Lin N., Dean A. and Ensel W. M.), p. 71. Academic Press, Orlando, 1986.

13. House J. S., Umberson D. and Landis K. R. Structures and processes of social support. A. Rev. Sociol. 14, 293, 1988.

14. Berkman L.F. The relationships of social networks and social support to morbidity and mortality. In Social
Support and Health (Edited by Cohen S. and Syme S. L.) p. 241. Academic Press, New York, 1985.

15. Bourdieu P. Le capital social. Notes provisoires. [The social capital. Preliminary notes] Actes Recherche Sci. Soc. 3, 2, 1980.

16. Flap H. Conflict, Loyalty, and Violence. Peter Lang, Frankfurt, 1988.

17. Coleman J. S. Social capital in the creation of human capital. Am. J. Sociol. 94, supplement s95, 1988.

18. Boxman E. A. W. Contacten en carrière. Een empirisch-theoretisch onderzoek naar de relatie tussen sociale netwerken en arbeidsmarktposities. (Contacts and careers. An empirical-theoretical study on the relationship between social networks and labor market positions). Thesis publishers, Amsterdam, 1988.

19. Campbell K. E., Marsden P. V. and Hurlbert J. S. Social resources and socioeconomic status. Soc. Networks 8,97, 1986.

20. Joosten J., Van der Horst F. and De Witte L. Chronische patienten en hun sociale contacten (Chronic patients and their social contacts). Paper for the Dutch-Flemish days for Sociologists, 1986.

21. Rounds K. A. and Israel B. A. Review. Social networks and social support: living with chronic renal disease. Patient Educ. Counseling 7, 227, 1985.

22. Litwak E. Helping the Elderly. The Complementary Roles of Informal Networks and Formal Systems. Guilford Press, New York/London, 1985.

23. Van den Brink-Muinen A. and Sixma H. De zorg voor ouderen in Almere (Care for the elderly in Almere). NIVEL, Utrecht, 1990.

24. Janssen M. Personal Networks of Chronic Patients. Datawyse, Maastricht, 1992.

25. Felling A. J. A., Fiselier A. A. M. and Van der Poel M. G. M. Primaire relaties en sociale steun. Achtergronden van de behoefte aan steun, de aard en de omvang van informele steunverlening en daarbij opgedane ervaringen (Primary relationships and social support. Backgrounds of the need for support, the type and amount of informal care-giving, and experiences with informal care). Instituut voor Toegepaste Sociale Wetenschappen, Nijmegen, 1992.

26. Cohen S. and McKay G. Social support, stress and the buffering hypothesis: a theoretical analysis. In Handbook of Psychology and Health, Vol. 4 (Edited by Baum A., Singer J. E. and Taylor S. E.), p. 253. Erlbaum, Hillsdale/New York, 1984

27. Cutrona C. E. and Russell D. W. Type of social support and specific stress: toward a theory of optimal matching. In Social Support: An Interactional View (Edited by Sarason B. R., Sarason I. G. and Pierce G. R.), p. 319. Academic Press, New York, 1990.

28. House J. S. and Kahn R. L. Measures and concepts of social support. In Social Support and Health (Edited by Cohen S. and Syme S. L.), p. 83. Academic Press, New York, 1985.

29. Schonfeld I. S. Dimensions of functional social support and psychological symptoms. Psychol. Med. 21, 1051 , 1991.

30. Lin N. Conceptualizing social support. In Social Support, Life Events, and Depression (Edited by Lin N., Dean A. and Ensel W. M.), p. 17. Academic Press, Orlando, 1986

31. Hobfoll S. E., Freedy J., Lane C. and Geller P. Conservation of social support resources: social support resource theory. J. Soc. Personal Relationships 7, 465, 1990.

32. Foets M., Van der Velden J. and de Bakker D. De Survey Design. National Study of Morbidity and Interventions in General Practice. NIVEL, Utrecht, 1992.

33. Foets $M$. and Van der Velden J. Een Nationale Studie van ziekten en verrichtingen in de huisartspraktijk. Basisrapport: Meetinstrumenten en procedures (National Study of 
morbidity and interventions in general practice. Basis-report: Measurements and procedures). NIVEL, Utrecht, 1990.

34. Ormel J. and Koeter M. W. J. De Groningse gebeurtenissen lijst (The Groningen events list). Academic Hospital, Department of Social Psychiatry, Internal publication, Groningen, 1985

35. Furer J. W. and $\operatorname{Tax}$ B. Somatische klachten, psychiatrische symptomen en psychosociale problemen. Prevalentie, overlappingen en verbanden met demografische variabelen (Somatic complaints, psychiatric symptoms and psychosocial problems. Prevalences, overlap en relations with demografic variables). Eindrapport van het Regioprojekt Nijmegen, deel 1. Instituut voor Sociale Geneeskunde, Katholieke Universiteit Nijmegen. ISG-publikatie nr. 17, 1987.

36. Lamberts $\mathrm{H}$. and Woods $\mathrm{M}$. International Classification of Primary Care. Oxford University Press, Oxford, 1987.

37. Goldberg D. The Detection of Psychiatric Illness by Questionnaire. Maudsley Monographs No. 21. Oxford University Press, London, 1972.

38. Tarnopolsky A., Hand D. J., McLean E. K., Roberts H. and Wiggins R. D. Validity and uses of a screening questionnaire (GHQ) in the community. Br. J. Psychiat. 134, 508, 1979.

39. Fischer C. S. To Dwell among Friends: Personal Networks in Town and City. Chicago University Press, Chicago, 1982.

40. Tijhuis M. A. R., Flap H. D., Foets M. and Groenewegen P. P. Netwerken in Nederland. Een onderzoek naar persoonlijke netwerken van Nederlanders (Networks in the Netherlands. A study of personal networks of the Dutch). Mens en Maatschappij 67, 5, 1992.

41. Van den Bos G. A. M. Zorgen van en voor chronisch zieken (Care for the chronically ill). Bohn, Scheltema and Holkema, Utrecht, 1989.

42. Van den Berg J. and Van den Bos G. A. M. Het (meten van het) voorkomen van chronische aandoeningen, 1974-1987 [The (measurement of the) prevalence of chronic conditions, 1974-1987]. Maandbericht Gezondheid 3, 4, 1989.

43. Van Sonsbeek J. L. A. Methodische en inhoudelijke aspecten van de OESO-indicator betreffende langdurige beperkingen in het lichamelijk functioneren (Methodological and substantial aspects of the OECD-indicator concerning long-lasting limitations in bodily functioning). Maandbericht Gezondheid 6, 4, 1988.
44. Hosmer D. W. and Lemeshow S. Applied Logistic Regression. John Wiley and Son, New York, 1989.

45. Weisberg S. Applied Linear Regression. John Wiley and Son, New York, 1985

46. Hays W. L. Statistics. Holt, Rinehar and Winston, New York, 1981 .

47. Dunkel-Schetter C. and Wortman C. B. The interpersonal dynamics of cancer: problems in social relationships and their impact on the patient. In Interpersonal Issues in Health Care (Edited by Friedman H.S. and DiMatteo M.R.), p. 69. Academic Press, New York, 1982.

48. Avis N. E., Brambilla D. J., Vass K. and McKinlay J. B. The effect of widowhood on health: a prospective analysis from the Massachusetts women's health study. Soc. Sci. Med. 33, 1063, 1991.

49. Ros W. J. G. Sociale steun bij kankerpatienten (Social support in cancer patients). Thesis Publishers, Amsterdam, 1990.

50. Glass T. A. and Maddox G. L. The quality and quantity of social support: stroke recovery as psycho-social transition. Soc. Sci. Med. 34, 1249, 1992.

51. Lin N. and Ensel W. M. Life stress and health: stressors and resources. Am. Sociol. Rev. 54, 382, 1989.

52. Schaefer C., Coyne J. C. and Lazarus R. S. The health-related functions of social support. J. Behav. Med. 4, 381, 1982.

53. Cohen S., Mermelstein R., Kamarck T. and Hoberman $H$. M. Measuring the functional components of social support. In Social Support: Theory, Research and Applications (Edited by Sarason I. G. and Sarason B. R.), p. 73. Martinus Nijhoff Publishers, Dordrecht, 1985.

54. Dooley D., Rook K. and Catalano R. Job and non-job stressors and their moderators. J. Occup. Psychol. 60, $115,1987$.

55. Ensminger M. E. and Celentano D. D. Unemployment and psychiatric distress: social resources and coping. Soc. Sci. Med. 27, 239, 1988.

56. Buehler C. and Legg B. H. Mothers' receipt of social support and their psychological well-being following marital separation. J. Soc. Personal Relationships 10,21, 1993.

57. Tijhuis M.A. R., Flap H. D., Foets M. and Groenewegen P. P. Kenmerken van sociale relaties en gezondheid (Characteristics of social relations and health). Tijdschrift voor Sociale Gezondheidszorg 7, 341, 1994.

\section{APPENDIX A}

Pearson's product moment correlations for stressful events, types of support, minor complaints, psychiatric complaints and feeling in bad health $(N=9662-10,110)$

\begin{tabular}{lccc}
\hline & $\begin{array}{c}\text { Minor } \\
\text { complaints }\end{array}$ & $\begin{array}{c}\text { Psychiatric } \\
\text { complaints }\end{array}$ & $\begin{array}{c}\text { Feeling in } \\
\text { bad health }\end{array}$ \\
\hline Emotional support, not related to health & $0.08^{* *}$ & $0.10^{* *}$ & $-0.09^{* *}$ \\
Practical support, not related to health & $0.05^{* * *}$ & $0.04^{* *}$ & $-0.02^{*}$ \\
Emotional support, related to health & $0.19^{* * *}$ & $0.13^{* * *}$ & $0.09^{* *}$ \\
Practical support, related to health & $0.19^{* * *}$ & $0.17^{* * *}$ & $0.16^{* * *}$ \\
Information, related to health & 0.01 & 0.01 & $-0.11^{* *}$ \\
Social problems requiring emotional support & $0.42^{* * *}$ & $0.53^{* * *}$ & $0.21^{* * *}$ \\
Social problems requiring practical support & $0.26^{* * *}$ & $0.33^{* * *}$ & $0.12^{* * *}$ \\
Life events requiring emotional support & $0.11^{* *}$ & $0.13^{* * *}$ & 0.01 \\
Life events requiring practical support & $0.11^{* *}$ & $0.12^{* *}$ & -0.01 \\
\hline
\end{tabular}

Statistical significance: ${ }^{*} P<0.05 ; * * P<0.01 ; * * * P<0.001$

Correlations between life events and chronic diseases are not included, because these diseases generally precede the events, and therefore these analyses would be causally incorrect. 
APPENDIX B

Pearson's product moment correlations for illness as stressor, types of support, and consequences of illness $(N=9106-10,110)$

\begin{tabular}{lcccc}
\hline & \multicolumn{3}{c}{ Number of days } \\
\cline { 2 - 5 } & \multicolumn{1}{c}{$\begin{array}{c}\text { Confined } \\
\text { to bed }\end{array}$} & $\begin{array}{c}\text { Quieting } \\
\text { disabilities }\end{array}$ \\
\hline Emotional support, not related to health & -0.01 & 0.01 & 0.01 & $-0.12^{* *}$ \\
Practical support, not related to health & $0.04^{* *}$ & $0.03^{* *}$ & $0.05^{* *}$ & $-0.03^{* *}$ \\
Emotional support, related to health & $0.08^{* *}$ & $0.04^{* *}$ & $0.10^{* * *}$ & $-0.03^{* *}$ \\
Practical support, related to health & $0.20^{* * *}$ & $0.16^{* * *}$ & $0.21^{* * *}$ & $0.22^{* * *}$ \\
Information, related to health & -0.01 & -0.01 & -0.01 & $-0.15^{* * *}$ \\
Chronic diseases requiring emotional support & $0.17^{* * *}$ & $0.11^{* * *}$ & $0.18^{* * *}$ & $0.41^{* * *}$ \\
Chronic diseases requiring practical support & $0.17^{* * *}$ & $0.12^{* * *}$ & $0.19^{* * *}$ & $0.39^{* * *}$ \\
Chronic diseases requiring information & $0.16^{* * *}$ & $0.10^{* * *}$ & $0.17^{* * *}$ & $0.38^{* * *}$ \\
Minor complaints requiring emotional support & $0.12^{* * *}$ & $0.14^{* * *}$ & $0.21^{* * *}$ & - \\
Minor complaints requiring practical support & $0.15^{* * *}$ & $0.14^{* * *}$ & $0.26^{* * *}$ & - \\
Minor complaints requiring information & $0.15^{* * *}$ & $0.13^{* * *}$ & $0.24^{* * *}$ & - \\
Psychiatric complaints & $0.22^{* * *}$ & $0.15^{* * *}$ & $0.26^{* * *}$ & - \\
Feeling in bad health & $0.23^{* * *}$ & $0.13^{* * *}$ & $0.25^{* * *}$ & - \\
\hline
\end{tabular}

Statistical significance: ${ }^{*} P<0.05 ;{ }^{* *} P<0.01 ;{ }^{* * *} P<0.001$.

Correlations for minor-, psychiatric complaints and feeling in bad health with number of disabilities are not included because these complaints are acute in contrast to the disabilities which may have been present for a longer period of time. These analyses would be causally incorrect.

\section{APPENDIX C}

Correlations between receipt of support and expected need for support

\begin{tabular}{|c|c|c|c|c|c|c|}
\hline & \multicolumn{2}{|c|}{$\begin{array}{l}\text { Support, not } \\
\text { related to health }\end{array}$} & \multicolumn{2}{|c|}{ Health-related support } & \multirow[b]{2}{*}{ Information } & \multirow[b]{2}{*}{$N$} \\
\hline & Practical & Emotional & Practical & Emotional & & \\
\hline $\begin{array}{l}\text { Number of: } \\
\text { Social problems requiring emotional support } \\
\text { Social problems requiring practical support } \\
\text { Life events requiring emotional support } \\
\text { Life events requiring practical support }\end{array}$ & $\begin{array}{r}0.01 \\
-0.02 \\
0.03 \\
0.03\end{array}$ & $\begin{array}{l}0.08^{*} \\
0.01 \\
0.06^{* *} \\
0.05\end{array}$ & $\begin{array}{c}0.07^{* *} \\
-0.01 \\
0.02 \\
0.01\end{array}$ & $\begin{array}{l}0.16^{* * *} \\
0.09^{* *} \\
0.07^{* *} \\
0.10^{* *}\end{array}$ & $\begin{array}{l}0.04^{* * *} \\
0.02^{*} \\
0.08^{* *} \\
0.08^{* *}\end{array}$ & $\begin{array}{r}3257 \\
661 \\
2283 \\
1748\end{array}$ \\
\hline $\begin{array}{l}\text { Chronic diseases requiring emotional support } \\
\text { Chronic diseases requiring practical support } \\
\text { Chronic diseases requiring information } \\
\text { Minor complaints requiring emotional support } \\
\text { Minor complaints requiring practical support } \\
\text { Minor complaints requiring information } \\
\text { Psychiatric complaints } \\
\text { Experienced health status } \\
\text { ( } 1=\text { very good, } 5=\text { very bad })\end{array}$ & $\begin{array}{r}-0.02 \\
-0.01 \\
-0.01 \\
0.01 \\
0.02 \\
0.03^{*} \\
-0.02 \\
-0.01\end{array}$ & $\begin{array}{l}-0.05^{* *} \\
-0.04^{*} \\
-0.05^{* *} \\
0.06^{* * *} \\
0.06^{* *} \\
0.05^{* *} \\
0.02 \\
\\
-0.05^{*}\end{array}$ & $\begin{array}{l}0.13^{* * *} \\
0.13^{* * *} \\
0.12^{* * *} \\
0.13^{* * *} \\
0.14^{* * *} \\
0.15^{* * *} \\
0.08^{* *} \\
0.09^{* *}\end{array}$ & $\begin{array}{l}0.01 \\
0.02 \\
0.03^{*} \\
0.13^{* * *} \\
0.14^{* * *} \\
0.13^{* * *} \\
-0.01 \\
-0.01\end{array}$ & $\begin{array}{l}-0.07^{* *} \\
-0.05^{* *} \\
-0.06^{* *} \\
0.01 \\
0.01 \\
-0.01 \\
-0.04 \\
-0.05\end{array}$ & $\begin{array}{l}5099 \\
4412 \\
5570 \\
6335 \\
7220 \\
6948 \\
1240 \\
1720\end{array}$ \\
\hline
\end{tabular}

Statistical significance: ${ }^{*} P<0.05 ; * * P<0.01 ;{ }^{* *} P<0.001$. 


\section{APPENDIX D}

Non-standardized linear regression coefficients for each type of support per dependent variable for people with illness as stressor and at least one day of neglecting, being confined to bed, or quieting, or at least one disability, analyses are controlled for gender $(0=$ female, $I=$ male), age (continuous), education $(I=$ low, through $5=$ high), and number of diseases or complaints in each group of diseases or complaints

\begin{tabular}{lcccc}
\hline & \multicolumn{3}{c}{ Number of days } \\
\cline { 2 - 5 } & \multicolumn{5}{c}{$\begin{array}{c}\text { Confined } \\
\text { to bed }\end{array}$} & Quieting & $\begin{array}{c}\text { Number of } \\
\text { disabilities }\end{array}$ \\
\hline (1) For people experiencing chronic diseases requiring emotional support \\
$N=$ & 977 & 256 & 984 & 2544 \\
Emotional support, not related to health & -0.11 & -0.11 & $-0.25^{*}$ & -0.01 \\
Practical support, not related to health & 0.30 & -0.04 & 0.01 & 0.05 \\
Emotional support, related to health & 0.55 & 0.13 & -0.02 & $0.09^{*}$ \\
Practical support, related to health & $1.30^{* * *}$ & $0.68^{* * *}$ & $0.78^{* * *}$ & $0.77^{* * *}$ \\
Information, related to health & -0.38 & $-0.48^{*}$ & -0.21 & $-0.11^{*}$ \\
(2) For people experiencing chronic diseases requiring practical support & & \\
$N=$ & 882 & 239 & 904 & 2241 \\
Emotional support, not related to health & -0.05 & -0.17 & -0.25 & -0.02 \\
Practical support, not related to health & 0.31 & -0.04 & 0.06 & 0.06 \\
Emotional support, related to health & 0.52 & 0.11 & -0.07 & $0.09^{*}$ \\
Practical support, related to health & $1.41^{* * *}$ & $0.63^{* *}$ & $0.74^{* * *}$ & $0.76^{* * *}$ \\
Information, related to health & -0.46 & $-0.50^{*}$ & -0.22 & $-0.13^{* *}$
\end{tabular}

(3) For people experiencing chronic diseases requiring information

$N=$

$1062 \quad 271 \quad 1042$

Emotional support, not related to health

Practical support, not related to health

$-0.16$

271

1042

0.28

-0.15
-0.01

$-0.30^{*}$
-0.02

2638

Emotional support, related to health

$0.62^{*}$

0.11

$-0.03$

$0.64^{* * *}$

$0.68^{* * *}$

$-0.02$

Practical support, related to health

$1.31 *$

$-0.45^{*}$

$-0.20$

0.04

0.07

$0.76^{* * *}$

$-0.12^{*}$

(4) For people experiencing minor complaints requiring emotional support

$N=\quad 1318 \quad 343 \quad 1228$

Emotional support, not related to health

Practical support, not related to health

Emotional support, related to health

Practical support, related to health

$-0.26$

$-0.07$

$-0.16$

$0.24 \quad 0.07$

$0.68 * *$

$1.49 * * *$

0.08

$-0.45$

$0.77^{* * *}$

0.07

$-0.46^{* *}$

0.15
$0.77^{*}$

$-0.10$

(5) For people experiencing minor complaints requiring practical support

$N=$

Emotional support, not related to health

Practical support, not related to health

Emotional support, related to health

Practical support, related to health

Information, related to health

1471
-0.22

$-0.22$

0.20

$0.64^{* *}$

$1.56^{* * *}$

360

$-0.09$

0.04

0.09

$0.73^{* * *}$

$-0.37^{*}$

1349

$-0.43$

(6) For people experiencing minor complaints requiring information

$N=$

1430

Emotional support, not related to health

Practical support, not related to health

Emotional support, related to health

Practical support, related to health

Information, related to health

$-0.21$

0.21

$0.62^{* *}$

$1.56^{* * *}$

$-0.46^{*}$

350
-0.08
0.06
0.10
$0.74^{* * *}$
$-0.40^{*}$
1323
-0.22
0.06
0.09
$0.79^{* * *}$
$-0.17$

(7) For people experiencing psychiatric complaints

$N=$

390

Emotional support, not related to health

Practical support, not related to health

Emotional support, related to health

Practical support, related to health

Information, related to health

(8) For people feeling in bad health

$N=$

$-0.81$

$-0.07$

$-0.31$

$1.19^{*}$

\section{1}

0.05

$-0.07$

$-0.18$

$0.76^{*}$

$-0.28$

$-0.10$

488

Emotional support, not related to health

Practical support, not related to health

Emotional support, related to health

Practical support, related to health

Information, related to health
$-0.08$

0.11

0.23

0.39

0.12

\section{9}

0.02

0.05

0.30

0.40

$-0.52$
415

$-0.19$

0.07

$-0.32$

$0.62^{* *}$

0.09

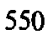

-0.08
-0.08
-0.08
$0.37 *$
-0.16

Statistical significance: ${ }^{*} P<0.05 ; * * P<0.01 ; * * P<0.001, t$-test.

Regression analyses for people experiencing minor-, psychiatric complaints and feeling in bad health with number of disabilities are not included because these complaints are acute in contrast to the disabilities which may have been present for a longer period of time. These analyses would be causally incorrect. 